\title{
DESESPERANZA EN JÓVENES: UN ANÁLISIS POR SEXO
}

\section{Despair in youth: an analysis by gender}

\author{
José Luis Valdez Medina* \\ , Mario Ulises Maya Martínez, Yessica Paola Aguilar Montes de Oca, Raúl \\ Bustillos, Patricia Antonio, Alma Valdés, Norma Ivonne González, Arratia \\ López Fuentes
}

\begin{abstract}
Resumen
La desesperanza genera desvalorización personal, que puede llevar a estados de depresión mayor. El objetivo fue describir las experiencias de desesperanza en una muestra de 224 jóvenes mexicanos de ambos sexos con un promedio de edad de 26 años. Se utilizó un cuestionario de nueve reactivos validado por jueces expertos. Los resultados muestran que las mujeres son quienes más frecuentemente la han experimentado. La falta de esperanza en los participantes se encuentra en las áreas: académica, laboral, económica, emocional, personal, accidentel enfermedad. Respecto de sus causas, las mujeres la atribuyen a factores internos y los hombres a factores externos. Los resultados dejan ver que vivir con desesperanza incrementa el riesgo de perder la estabilidad y la salud en general.
\end{abstract}

Palabras clave: Desesperanza, jóvenes, México, hombres, mujeres.

\begin{abstract}
Despair generates personal devaluation, which can lead to states of greaterdepression. The aim was to describe experiences of despair in a sample of 224 Mexican youths of both genders aged 26 on average. A questionnaire of nine reagents validated by expert judges was used. The results show that women have experienced it more frequently. Lack of hope in participants is evidenced in the following areas: academic, occupational, economic, emotional, personal, accident / illness. With regard to the causes, women attribute it to internal factors whilemen to external factors. The results reveal that livingin despair increases the risk of losing stability and health in general.
\end{abstract}

Keywords: Despair, youths, Mexico, men, women.

\footnotetext{
* Psicólogo. Docente de la Facultad de Ciencias de la Conducta Universidad Autónoma del Estado de México.ochocedros2@gmail.com
} 


\section{INTRODUCCIÓN}

Los seres humanos se encuentran inmersos en la dinámica apremiante, de conseguir o conservar los recursos o satisfactores que le permitan cubrir las necesidades o carencias propias de su supervivencia, mientras buscan evitar e incluso desaparecer las amenazas o miedos que le alejan de una vida en equilibrio (Valdez Medina, 2009).

Debido a la importancia de esta dinámica, cuando no es posible evitar una amenaza, o no es posible conseguir o conservar lo que esperaba, el individuo experimenta frustración como primer emoción negativa (Alvarado, 2014). Si la amenaza permanece, es probable que el sujeto no crea posible la resolución de la situación, e incluso que presente una falla para integrar las experiencias exitosas que contradigan la visión negativa que tiene de sí mismo, llevándolo a experimentar desesperanza (Valdez Medina, 2009; González y Hernández, 2012).

La desesperanza ha sido planteada como un déficit cognitivo, motivacional y emocional, que surge a partir de eventos incontrolables. Se presenta como un sentimiento de pérdida de ánimo, la imposibilidad de poder imaginar que algo mejor pueda ocurrir, o el hecho de perder la confianza de que las cosas pueden cambiar y ser mejores (Seligman, 1975; Córdova, Rosales y Eguiluz, 2005).

Durante mucho tiempo se consideró como un estado sensorial difuso, vago y amorfo, hasta que se planteó su medición considerando manifestaciones afectivas, motivacionales y cognitivas en adultos (Beck, Weissman, Lester y Trexler, 1974).

De acuerdo con Beck (1976), la desesperanza tiene dos características principales: aplanamiento emocional y un autoconcepto negativo. Debido a esto, el individuo experimenta sentimientos de desesperación, decepción y desilusión.

Debido a ello, autores como Quintanilla, Haro, Flores, Celis y Valencia (2003), indican que la desesperanza es un estado dinámico de actitud y percepciónquelapersonatienesobrelosacontecimientos venideros, de tal manera que condicionan u orientan la conducta del individuo sobre el qué hacer. Plantearlo como un estado dinámico, es reconocer que el estar en desesperanza es el resultado de un proceso, valorado en un momento y circunstancias determinadas, y sujeto a situaciones de cambio positivo o negativo.

El riesgo de esta situación, es que, de presentar estos síntomas de manera frecuente, la persona podría derivar en un episodio depresivo mayor, ya que ésta condiciona, orienta e induce a un estado de indefensión que comporta la reducción o anulación de la motivación extrínseca por no poder alcanzar resultados positivos o evitar los negativos, es decir, genera en los sujetos el abandono de búsqueda de solución al problema (APA, 1994; La Frombiose y Pitney, 1995; Pichot, 1995; Quintanilla, Haro, Flores, Celis y Valencia, 2003; González y Hernández, 2012), por lo que también se ha considerado a la desesperanza como un predictor sensible del comportamiento suicida (Córdova y Rosales, 2010).

Particularmente en México, se observa que un importante número de jóvenes vive con desesperanza, lo que se traduce en desvalorización y una suerte de anomia social (Cisneros y Zubillaga, 2001). Dichos autores aseguran que la principal problemática radica en que un gran número de ellos ve que sus expectativas de cara al futuro se han desvanecido, haciendo énfasis en que la economía mexicana ha crecido ya no se diga por debajo de las expectativas, sino por debajo de las necesidades. Ubicando a los jóvenes como el grupo más vulnerable del país para experimentar desesperanza e incluso pensamientos suicidas (Briceño, 1991 y González y Hernández, 2012).

Por ello, el objetivo de la presente investigación consistió en describir las experiencias de desesperanza en jóvenes de ambos sexos de una muestra mexicana.

\section{MÉTODO}

\section{Participantes}

Se utilizó una muestra no probabilística de tipo intencional compuesta por 224 adultos residentes de la ciudad de Toluca, Estado de México (45.08 \% hombres y $54.92 \%$ mujeres), con una media de edad de 26 años. 


\section{Instrumento}

Se construyó un cuestionario compuesto por 9 reactivos en forma de preguntas abiertas, que permiten describir las experiencias de desesperanza que presentan los participantes. El instrumento se validó mediante un análisis por jueces expertos, obteniendo un acuerdo mayor al $85 \%$. Las preguntas que integran al instrumento fueron: ¿Alguna vez has perdido la esperanza de conseguir o evitar algo?, ¿Qué tratabas de conseguir o evitar que no lograste, y te llevo a perder la esperanza de poder conseguirlo o evitarlo?, ¿Qué lo impidió, qué estorbó, interfirió u obstaculizó para que no consiguieras o evitaras?, ¿Qué hiciste en ese momento?, ¿Emocionalmente cómo te sentiste al no poder conseguirlo?, ¿Qué síntomas tuviste cuando experimentaste esta situación?, ¿Por fin conseguiste lo que buscabas?, Si no lo conseguiste ¿con qué lo sustituiste, compensaste o con qué lo intercambiaste para no sentir la desesperanza?, ¿Consideras que ya lo resolviste o que todavía sigue presente en tu vida?, ¿Qué sientes al recordar esa situación?

\section{Procedimiento}

Previa autorización de los participantes, las aplicaciones se realizaron de manera individual, en centros educativos y laborales de la Ciudad de Toluca, Estado de México, en un tiempo aproximado de 30 minutos por participante.

\section{RESULTADOS}

De acuerdo con los resultados obtenidos para la pregunta ¿Alguna vez has perdido la esperanza de conseguir o evitar algo?, se observa que tanto hombres como mujeres han perdido la esperanza de conseguir o evitar algo, aunque a las mujeres les ha sucedido con mayor frecuencia que los hombres (ver tabla 1 ).
Tabla 1.

¿Alguna vez has perdido la esperanza de conseguir o evitar algo?

\begin{tabular}{ccc}
\hline RESPUESTA & HOMBRES & MUJERES \\
\hline $\mathrm{Si}$ & $36.5 \%$ & $49 \%$ \\
$\mathrm{No}$ & $7.6 \%$ & $6.8 \%$ \\
Total & $100 \%$ & \\
\hline
\end{tabular}

Con respecto a la pregunta ¿Qué tratabas de conseguir o evitar que no lograste, y te llevó a perder la esperanza de poder conseguirlo o evitarlo?, se encontró que ambos sexos trataban de conseguir o evitar lo relacionado con algún aspecto académico, laboral, económico, afectivo, personal, accidentes/ enfermedad y la muerte. En las mujeres se agregó la categoría de problemas familiares.

De manera particular se encontró que los hombres se preocupan más por conseguir o evitar cuestiones personales y afectivas y las mujeres cuestiones académicas (ver tabla 2). 
Tabla 2.

¿Qué tratabas de conseguir o evitar que no lograste, y te llevó a perder la esperanza de poder conseguirlo o evitarlo?

\begin{tabular}{ll}
\hline CATEGORÍA & \multicolumn{1}{c}{ HOMBRES } \\
\hline Académico & $\begin{array}{l}\text { Calificaciones, entrar a un curso, obtener } \\
\text { o conservar una beca, } \\
\text { Terminar de estudiar una carrera, un } \\
\text { director de tesis adecuado, terminar } \\
\text { estudios con excelente calificación. }\end{array}$ \\
Laboral & $\begin{array}{l}\text { Conseguir un trabajo. } \\
\text { Económico }\end{array}$ \\
& $\begin{array}{l}\text { Crisis económica, } \\
\text { económica, obtener ingresos económicos, } \\
\text { comprar un camión, automóvil, material } \\
\text { para entretenimiento, comprar una } \\
\text { computadora. }\end{array}$ \\
Afectivos & $\begin{array}{l}\text { No pude conservar a la pareja, iniciar } \\
\text { una relación con alguien, el afecto o amor } \\
\text { de una mujer, asimilar la situación y } \\
\text { vivir el momento de amor, amor, hablarle }\end{array}$ \\
a las personas que me gustan, dejar una \\
relación, pérdida de una relación de \\
amistad.
\end{tabular}

$10.34 \%$ No pude conservar a la pareja, iniciar una

$5.95 \%$ Ver que no podía hacer las cosas como

$1.65 \%$ Ataques de ansiedad que me dan, evitar que

$3.1 \%$ Muerte de un Familiar, la muerte de alguien.
Problemas familiares
Actuar en contra de mis convicciones, mantener mi físico, competencias deportivas, ir al extranjero, que se descubriera una mentira, viajar a Estados Unidos, viajar, el campeonato de la liga de futbol
Accidentes/ Una lesión en las piernas. seres queridos.
Muerte $\quad$ Muerte de un familiar, pérdida, muerte de
Personal relación con alguien;

circunstancia emocional, cambiar expectativas de mi pareja, trataba de no lastimas a la persona que ame, estar con la persona que ame, amor, mi pareja comprendiera que yo quiero carrera y no familia ahora, concretar el matrimonio y vivir con mi novio, ayudar a una persona, que un amigo me hablara, la virtud del encuentro con el otro. quería. mi padre enferme.

$\%$

$25.72 \%$

0\% El perdón de mis padres, detener una riña, evitar que se fuera mi hermano (a) de la casa, una relación familiar, la unión y estabilidad en mi familia, arreglar un problema con mi mamá, pelearme con mi hermano y dejarnos de hablar. 
En cuanto a la pregunta ¿Qué lo impidió, qué estorbó, interfirió u obstaculizó para que no consiguieras o evitaras?, los resultados se agruparon en dos categorías: factores internos y factores externos. Dentro de los primeros se encuentran el miedo, la falta de compromiso, disciplina y organización. La categoría de factores externos agrupa los problemas familiares, la falta de dinero, falta de tiempo.

Las diferencias muestran que para las mujeres en más alto porcentaje, fueron los factores internos entre los que se encuentran la falta de atención, de responsabilidad, distractores, la desconfianza, su orgullo y sentimientos negativos; mientras que para los hombres describen la timidez, la inseguridad, la incapacidad, falta de comprensión, de indecisión y celos. Respecto a los factores externos, se observa que los hombres son quienes presentan el más alto porcentaje, mencionando el chantaje, que no creyeran en él, falta de disposición, muerte, pérdida y ausencia, mientras que las mujeres mencionan la sociedad, los amigos, la familia de su ex, una enfermedad y la indecisión o problemas de otra persona (ver tabla 3).

Tabla 3

¿Qué lo impidió, qué estorbo, interfirió u obstaculizó para que no consiguieras o evitaras?

\begin{tabular}{ll}
\hline CATEGORÍA & HOMBRES \\
\hline Factores & $\begin{array}{l}\text { Miedo, esforzarme, más/mayor compromiso, } \\
\text { internos } \\
\end{array}$ \\
& $\begin{array}{l}\text { falta de disciplina y organización, timidez, } \\
\text { no comprensión de la situación, falta de }\end{array}$ \\
& decisión, celos, falta de conocimientos, \\
& malas decisiones, conflictos internos, me \\
& enfermé, falta de experiencia, yo mismo, baja \\
& autoestima, inmadurez.
\end{tabular}

Factores Problemas familiares, falta dinero, falta externos de tiempo, chantaje, que no creyeran en el proyecto, falta de disposición, muerte, pérdida, ausencia, obligaciones familiares, interés material, no verdadero amor, distancia, invención de cosas, enfermedad, errores de equipo, falta de experiencia, relación amorosa del momento, terceras personas, escolaridad, diferencias culturales, termino de la escuela, intereses, promedio, un mal resultado en el examen, dejarme llevar por los vicios, comprar otras cosas más necesarias, una operación, represalias de directivos, problemas con la calculadora, escolaridad.

\section{$\%$}

MUJERES

$\%$

$19.68 \%$ Miedo, esforzarme más/mayor compromiso,falta $25.90 \%$ de disciplina y organización, falta de atención, responsabilidad, distractores, la desconfianza hacia otros, mi orgullo, sentimientos negativos, miedo al qué dirán, inseguridad, estaba enferma, estudiar y no dar espacio a la relación, no llevaba las expectativas, mi columna, vanidad, mis prejuicios; indecisión, mi misma, mala decisión, falta de valentía, me case, la actitud, falta de comunicación, no pude aprender inglés rápido, no entrar a bachillerato, no me sentía bonita

$31.08 \%$ Problemas familiares, falta dinero, falta de $23.31 \%$ tiempo, la sociedad, amigos, la familia de mi ex, una enfermedad de él, la indecisión de otra persona, él tenía problemas y se fue, enfermedad terminal, no estaba en mis manos, por ser menor de edad no pude donar sangre, ya no me amaba/ quería, burocracia, la opinión de mis amigos, la persona, el contexto, un examen, el rompimiento, un nuevo amor, lo que esta persona ya no siente, insulto de un maestro, la demanda en la carrera.
Para la pregunta ¿Qué hiciste en ese momento?, las respuestas de los participantes se agruparon en dos factores: la movilidad o la inmovilidad. Respecto a la movilidad, los participantes concuerdan en que buscaron alejarse, conseguir trabajo, y tomarse un tiempo para reflexionar. Mientras que aquellos que tendieron a la inmovilidad mencionaron: llorar, nada, deprimirme, desesperación, enojarme y resignarme. 
Las diferencias muestran que son las mujeres quienes presentan un mayor porcentaje en la categoría de inmovilidad, mostrando que ellas aceptan las cosas, no pierden la fe, tienen pensamientos suicidas, se preocupan, muestran seriedad, inquietud y tristeza. Por su parte, los hombres presentan un mayor porcentaje en la categoría de movilidad, mencionando aspectos como: tratar de mantener a la persona, comenzar una nueva vida, independizarme, terminar la relación, buscar nuevas oportunidades, realizar otras actividades para ocupar el tiempo libre (ver tabla 4).

Tabla 4

¿Qué hiciste en ese momento?

\begin{tabular}{ll}
\hline CATEGORÍA & \multicolumn{1}{c}{ HOMBRES } \\
\hline Movilidad & $\begin{array}{l}\text { Alejarme, conseguir trabajo, darme tiempo } \\
\text { para pensar/ reflexionar, traté de mantener }\end{array}$ \\
a la persona, comenzar una nueva vida, \\
independizarme, terminar la relación, buscar \\
nuevas oportunidades, buscar otras escuelas, \\
buscar becas, realizar actividades que \\
ocuparan el tiempo libre, despedirse, dejarla \\
ir, olvidarla, golpear cosas, enfocarme en mis \\
estudios, pasar más tiempo con la persona, ir \\
al gimnasio, tomar clases extracurriculares, \\
ser más sobre protector, conseguí dinero con \\
unas ventas, brindar apoyo, entrenar por las \\
tardes, buscar ayuda, cambiarme de carrera, \\
otras actividades, tratar de olvidarla, salir con \\
otras personas, estudiar más.
\end{tabular}

Inmovilidad Llorar, nada, deprimirme, desesperación, enojarme resignarme, aceptar las cosas, cuestionar el porqué de las cosas, no perder la fe, pensamientos suicidas, preocuparme, seriedad, inquietud, tristeza, impotencia, indiferente, respirar, estar solo, no desesperarme, nerviosismo, me sentí culpable, me sentí dolido, evitar pensar en eso, aceptarlo, evadir la situación, fingir que nada paso.
25.64\% Alejarme, conseguí un trabajo, darme tiempo $15.38 \%$ para pensar/ reflexionar, tomar asesorías, optar por otra carrera, darles tiempo para asimilarlo; aceptarlo, comprensión, defenderlos a pesar de que me pegaran, todo lo posible, tomar peores decisiones y cometer más errores, intentarlo de nuevo, salir con él como amigos con derecho, dejarlo que incluso me pegara, regresar a estudiar, seguir adelante; buscar otra opción, comenzar otros planes; aguantar y cooperar, fui egoísta, intentar la comunicación, sernos infieles, otras actividades, tratar de olvidarlo, salir con otras personas o chavos que también me gustaran, estudié más tiempo y antes para los exámenes.

42.30\% Llorar, nada, deprimirme, desesperación, $16.67 \%$ enojarme, resignarme, quise desertar, enfocarme en algo más, trate de buscar soluciones, perder esperanza, evadir el tema, me frustre, no presenté el examen por pensar que no lo pasaría, me enoje, pensaba en morir, ocultarlo, arrepentirme, orar, pensar que después tendría mejores oportunidades, fingir fortaleza, me sentí mal, dejar que las cosas se solucionaran solas, evadir con alcohol y drogas, observar estática, sentir coraje contra las enfermeras, evitar a la persona, tomar todo positivamente, estar irritada, llorar, sólo quería dormir, me pregunté que había hecho mal
Respecto a la pregunta ¿Emocionalmente cómo te sentiste al no poder conseguirlo? Las respuestas se agruparon en los factores de tristeza, ansiedad, frustración, odio, malestar y optimismo.
En particular las mujeres mencionan más aspectos relacionados con la tristeza, odio y malestar. Mientras, los hombres mencionan más que las mujeres a la frustración y el optimismo (ver tabla 5). 
Tabla 5

¿Emocionalmente cómo te sentiste al no poder conseguirlo?

\begin{tabular}{|c|c|c|c|c|}
\hline \multicolumn{2}{|c|}{ CATEGORÍA } & \multirow{2}{*}{$\frac{\%}{11.77 \%}$} & MUJERES & \multirow{2}{*}{$\frac{\%}{19.91 \%}$} \\
\hline Tristeza & $\begin{array}{l}\text { Tristeza, sin ganas/ depresión, ganas de llorar, } \\
\text { desilusión, desconsolado, apático de la vida. }\end{array}$ & & $\begin{array}{l}\text { Tristeza, depresión, ganas de llorar, } \\
\text { desilusión, decepcionada, pena, devastado, } \\
\text { desánimo, empequeñecimiento, pocas ganas } \\
\text { de seguir adelante. }\end{array}$ & \\
\hline Ansiedad & $\begin{array}{l}\text { Miedo, angustia, ansiedad intranquilo, euforia, } \\
\text { incertidumbre. }\end{array}$ & $4.28 \%$ & $\begin{array}{l}\text { Miedo, angustia, ansiedad, } \\
\text { remordimiento, desconfianza. }\end{array}$ & $4.28 \%$ \\
\hline Frustración & $\begin{array}{l}\text { Frustración, decepción, impotencia, } \\
\text { desesperación. }\end{array}$ & $13.06 \%$ & $\begin{array}{l}\text { Frustración, decepción, impotencia, } \\
\text { desesperación, fracaso. }\end{array}$ & $9.63 \%$ \\
\hline Odio & $\begin{array}{l}\text { Coraje, rencor, molesto conmigo, enojo, } \\
\text { resentido, odio, rabia, ira. }\end{array}$ & $9.42 \%$ & $\begin{array}{l}\text { Coraje, rencor, molesto conmigo, enojo, } \\
\text { resentido, odio, a punto de explotar. }\end{array}$ & $11.99 \%$ \\
\hline Malestar & Mal, dolor, culpa, baja autoestima, fatal. & $3.64 \%$ & $\begin{array}{l}\text { Mal, dolor, culpa, baja autoestima, } \\
\text { dolor de cabeza, egoísmo, muy tonta. }\end{array}$ & $4.93 \%$ \\
\hline Optimismo & $\begin{array}{l}\text { Optimismo, nada, tranquilo, alegría, felicidad, } \\
\text { sensatez }\end{array}$ & $4.72 \%$ & Optimista, nada, resignación. & $2.35 \%$ \\
\hline TOTAL & & $100 \%$ & & \\
\hline
\end{tabular}

En la pregunta ¿Qué síntomas tuviste cuando experimentaste esta situación? Se encontró que ambos sexos presentan malestares corporales como dolor de estómago, garganta cerrada, cansancio, dolor de espalda, presión en el pecho, problemas de presión, falta de aire, dolor de cabeza, y malestares psicológicos como mal humor.
Las diferencias por sexo muestran que las mujeres presentan con mayor frecuencia tanto malestares corporales como malestares psicológicos en comparación con los hombres (ver tabla 6).

Tabla 6

¿Qué síntomas tuviste cuando experimentaste esta situación?

\begin{tabular}{ll}
\hline CATEGORÍA & \multicolumn{1}{c}{ HOMBRES } \\
\hline $\begin{array}{l}\text { Malestar } \\
\text { corporal }\end{array}$ & $\begin{array}{l}\text { Dolor de estómago, garganta cerrada, nudo, } \\
\text { cansancio, dolor de espalda, presión en el } \\
\text { pecho, enfermo, problemas de presión arterial, } \\
\text { dolor de cabeza, falta de aire, raro, dolor de } \\
\text { tobillos, cansado, con hambre, gastritis. }\end{array}$
\end{tabular}

Malestar Mal humor, cansado y sin ganas de vivir. psicológico

$\% \quad$ MUJERES

$\%$

$30.95 \%$ Dolor de estómago, garganta cerrada, nudo, $43.06 \%$ cansancio, dolor de espalda, presión en el pecho, enferma, problemas de presión arterial, dolor de cabeza, vómito/nauseas, gripa, pérdida del apetito, mareos, con sed, dolor en el brazo, dolor muscular, insomnio.

7.88\% Mal humor, enojo, decaída/desanimado/débil, $18.06 \%$ tristeza, estrés, con angustia, inmóvil como si estuviera atada, con pocas ganas de trabajar, problemas para tomar decisiones, muchas ganas de dormir. 
En cuanto a la pregunta ¿Por fin conseguiste lo que buscabas?, se encontró que las mujeres en comparación con los hombres, son las que consiguieron con mayor frecuencia lo que se buscaban (ver tabla 7).

Tabla 7

¿Por fin conseguiste lo que buscabas?

\begin{tabular}{lcc}
\hline RESPUESTA & HOMBRES & MUJERES \\
\hline $\mathrm{Si}$ & $17.33 \%$ & $31.55 \%$ \\
$\mathrm{No}$ & $27.55 \%$ & $23.55 \%$ \\
TOTAL & $100 \%$ & \\
\hline
\end{tabular}

Con respecto a los resultados de la pregunta: $\mathrm{Si}$ no lo conseguiste, ¿con qué lo sustituiste, compensaste o con que lo intercambiaste para no sentir la desesperanza? Se obtuvieron las categorías de: optimismo, perseverancia, realizar otra actividad, evasión, compañía y sin sustitución.

La categoría más amplia para ambos es la que habla de la no sustitución, seguida de realizar otra actividad, evasión y perseverancia. Cabe mencionar que en todas las categorías puntuaron más altas las mujeres en comparación con los hombres (ver tabla 8).

Tabla 8

Si no lo conseguiste, ¿con qué lo sustituiste, compensaste o con qué lo intercambiaste para no sentir la desesperanza?

\begin{tabular}{|c|c|c|c|c|}
\hline CATEGORÍA & HOMBRES & $\%$ & MUJERES & $\%$ \\
\hline Optimismo & $\begin{array}{l}\text { Optimismo, aceptar la realidad, considerar } \\
\text { otras expectativas positivas, sustituirlo con } \\
\text { alegría y felicidad, }\end{array}$ & $3.16 \%$ & $\begin{array}{l}\text { Optimismo, realizarme como persona, } \\
\text { teniendo más cuidado, con la oración, conocer } \\
\text { gente nueva. }\end{array}$ & $6.4 \%$ \\
\hline Perseverancia & $\begin{array}{l}\text { Trabajando, sigo intentándolo, darme tiempo, } \\
\text { buscarla próximamente, la volví a cursar, } \\
\text { estoy en curso de alcanzarlo }\end{array}$ & $4.74 \%$ & $\begin{array}{l}\text { Trabajando, optar por otra carrera, entrar } \\
\text { (buscar) a otra opción educativa (UAEM, } \\
\text { letras), hacer examen de admisión para } \\
\text { otras universidades, estudiar aún más (más } \\
\text { empeño), seguir mi carrera }\end{array}$ & $7.68 \%$ \\
\hline $\begin{array}{l}\text { Realizar otra } \\
\text { actividad }\end{array}$ & $\begin{array}{l}\text { Practicando otro deporte, enfocarme en otras } \\
\text { cosas, mejorar la relación con mi familia, } \\
\text { estudios, con videojuegos, comprarme } \\
\text { una computadora, salir de viaje, trabajo } \\
\text { profesional, ejercicio, distraerme, } \\
\text { ocupaciones diversas }\end{array}$ & $12.17 \%$ & $\begin{array}{l}\text { Practicando otro deporte, tomar cursos, } \\
\text { aprovechar para hacer nuevos planes, compré } \\
\text { otro que me gusta mucho y es más barato, esa } \\
\text { persona ya no sufre, leo libros, veo TV, salir a } \\
\text { varias fiestas, me encontré en otra cosa, entré } \\
\text { a otra actividad, }\end{array}$ & $13.93 \%$ \\
\hline Evasión & $\begin{array}{l}\text { Olvidarlo, no darle importancia, tratar de no } \\
\text { pensar en él, poner en descubierto a otras } \\
\text { personas, gastar dinero. }\end{array}$ & $3.43 \%$ & $\begin{array}{l}\text { Fingir que nada paso, tomar alcohol, hacerme } \\
\text { la fuerte para ayudar a mis padres, con comida, } \\
\text { pensar que estaba en el mejor lugar, me aíslo } \\
\text { del mundo. }\end{array}$ & $6.16 \%$ \\
\hline Compañía & Salir con amigos, otra persona (amor). & $3.43 \%$ & $\begin{array}{l}\text { Salir con amigos, hablando con familia/ } \\
\text { amigos. }\end{array}$ & $6.80 \%$ \\
\hline Sin sustitución & No sustituí, nada. & $15.00 \%$ & $\begin{array}{l}\text { No lo pude sustituir, con nada, sigo con mi } \\
\text { frustración, sigo buscando ser la misma, estoy } \\
\text { en proceso. }\end{array}$ & $17.06 \%$ \\
\hline TOTAL & & $100 \%$ & & \\
\hline
\end{tabular}


En cuanto a la pregunta ¿Consideras que ya lo resolviste o que todavía sigue presente en tu vida?, se obtuvieron las categorías de: lo resolvió y la de sigue presente. Las diferencias por sexo muestran que las mujeres mencionan con mayor frecuencia haber resuelto la situación generadora de desesperanza mientras que los hombres comentan que sigue presente en sus vidas (ver tabla 9).

Tabla 9

¿Consideras que ya lo resolviste o que todavía sigue presente en tu vida?

\begin{tabular}{lllll}
\hline CATEGORÍA & HOMBRES & $\%$ & MUJERES & $\%$ \\
\hline
\end{tabular}

Lo Ya lo resolví, ya lo supere, dejé el pasado

resolvió atrás, conseguí el empleo.

Sigue Sigue presente, no lo he olvidado, está

presente la intención de conseguirla, con poca frecuencia.
$20.67 \%$

Ya lo resolví, ya lo supere, está olvidado, lo $26.93 \%$ resolví pero tengo situaciones similares, ya lo olvide y trato de hacer las cosas mejor, no lo he visto de nuevo, logré salir adelante trabajando, no, porque después logré conseguirlo.

$27.88 \%$ Sigue presente, no lo he olvidado, está la intención de conseguirla, continuamente pienso en ello, trato de evitar que me afecte, sé que lo podre resolver en otra oportunidad ya que no es primordial, lo recuerdo y creo que sirvió de algo, sigue como una experiencia de la que debo aprender, me sigue costando estar animado, algún día voy a viajar a ese país, aún busco salir de intercambio.
Finalmente, los resultados obtenidos en la pregunta, ¿Qué sientes al recordar esa situación?, se encontraron las categorías de: emociones positivas, emociones negativas, conflicto resuelto, conflicto no resuelto y nada.

De manera general se observa que ambos dicen sentir felicidad, confianza, tristeza, coraje, frustración, no sintieron lo mismo, o bien, sigue presente con menor intensidad, aún sienten arrepentimiento, aún lo recuerdan o no sienten nada.

Las diferencias por sexo indican que los hombres con mayor frecuencia sintieron alguna emoción positiva, resolvieron el conflicto y sintieron alguna emoción negativa, mientras que las mujeres dijeron no sentir nada, sentir emociones negativas y emociones positivas (ver tabla 10). 
Tabla 10

¿Qué sientes al recordar esa situación?

\begin{tabular}{|c|c|c|c|c|}
\hline CATEGORÍA & HOMBRES & $\%$ & MUJERES & $\%$ \\
\hline $\begin{array}{l}\text { Emociones } \\
\text { positivas }\end{array}$ & $\begin{array}{l}\text { Felicidad/Feliz, mayor confianza, más } \\
\text { maduro, con más energía, ilusión, me siento } \\
\text { pleno, mejoré como estudiante, tranquilo. }\end{array}$ & $11.42 \%$ & $\begin{array}{l}\text { Felicidad/Feliz, confianza ya que puedo superarlo, } \\
\text { más segura, cambio mi forma de pensar, pienso en } \\
\text { las posibles consecuencias. }\end{array}$ & $13.14 \%$ \\
\hline $\begin{array}{l}\text { Emociones } \\
\text { negativas }\end{array}$ & $\begin{array}{l}\text { Tristeza, coraje, frustración, melancolía, } \\
\text { desesperanza, impotencia, miedo, recuerdos } \\
\text { desagradables. }\end{array}$ & $9.71 \%$ & $\begin{array}{l}\text { Tristeza, coraje, frustración, angustia, rencor, } \\
\text { desilusión. }\end{array}$ & $15.99 \%$ \\
\hline $\begin{array}{l}\text { Conflicto } \\
\text { Resuelto }\end{array}$ & $\begin{array}{l}\text { No siento lo mismo, ya lo supere, aprendí de } \\
\text { los errores, no guardo rencor, no me preocupa, } \\
\text { no odio, no siento remordimiento, solo es un } \\
\text { recuerdo, siento que cuando tenga los recursos } \\
\text { y el tiempo lo cumpliré, ya no hay dolor. }\end{array}$ & $10.85 \%$ & $\begin{array}{l}\text { No siento lo mismo, no es lo mismo, mis intereses } \\
\text { han cambiado, era un sueño ahora es una meta, } \\
\text { ahora comprendo a mi familia, orgullosa de estar } \\
\text { con ellos, procuro mantener mi constancia para } \\
\text { sentirme mejor. }\end{array}$ & $4.57 \%$ \\
\hline $\begin{array}{l}\text { Conflicto } \\
\text { no resuelto }\end{array}$ & $\begin{array}{l}\text { Sigue presente con menor intensidad, aún } \\
\text { siento arrepentimiento, aún lo recuerdo. }\end{array}$ & $4 \%$ & $\begin{array}{l}\text { Sigue presente con menor intensidad, aún siento } \\
\text { arrepentimiento, aún lo recuerdo, no ha cambiado } \\
\text { nada,impaciencia, a veces me preocupa, de lo malo } \\
\text { busco lo bueno, ha incrementado la intensidad, } \\
\text { solo siento resignación. }\end{array}$ & $6.85 \%$ \\
\hline Nada & Nada, indiferencia. & $7.42 \%$ & Nada. & $16.05 \%$ \\
\hline TOTAL & & $100 \%$ & & \\
\hline
\end{tabular}

\section{DISCUSIÓN}

Con base en los resultados obtenidos, se observa que los participantes de ambos sexos han experimentado desesperanza, sin embargo, son las mujeres quienes mencionan experimentarla con mayor frecuencia. Esto se encuentra relacionado con las condiciones de vida actuales que ubican a la mujer en una situación no sólo de cumplir con el estereotipo tradicional femenino sino desempeñar múltiples roles en diferentes ámbitos (Díaz Guerrero, 1982; Aguilar, Valdez Medina y González Arratia, 2012), lo que de acuerdo con Garay y Farfán (2007) y Valdez Medina (2009), las ubica como más proclives a sufrir desesperanza e incluso, depresión.

De manera general, aquello que genera desesperanza en los participantes tienen que ver con aspectos académicos, laborales, económicos, afectivos, personales, accidentes/ enfermedad. Para los hombres lo económico, personal afectivo, los accidentes o enfermedad y la muerte representan aquello que los ubicó con más frecuencia en desesperanza.

La preocupación económica y la búsqueda de salud se encuentran íntimamente relacionados con el rol tradicional del hombre en México (Díaz-Loving, Díaz-Guerrero, Helmreich y Spence, 1981; Díaz Guerrero, 1982), mismo que lo habría dirigido hacia ser promovedor y protector de la familia, aspectos que de acuerdo con Buss (2005), tienen un amplio sustrato biológico. Tanto la solvencia económica como la salud física ubican al individuo en una posición favorable para cumplir de forma adecuada con dicho rol.

Resulta interesante resaltar que el aspecto académico y el laboral, han sido más mencionados por las mujeres, ello se debe a la tendencia actual del sexo femenino a desarrollarse académicamente, algo que no sucedía en generaciones pasadas (Valdez Medina, Díaz Loving y Pérez, 2005; Aguilar, Valdez-Medina y González Arratia, 2012).

Los problemas familiares representan también una fuente importante de desesperanza para las mujeres, ello se correlaciona con los hallazgos reportados por Alvarado (2014), quien menciona que la familia ha sido identificada como uno de los grupos sociales en donde se experimenta más agresión y sufrimiento. 
Respecto a lo que los participantes comentan que les impidió conseguir o conservar algo, se encontraron factores internos y factores internos. Las mujeres mencionan que fueron factores internos como la falta de atención, de responsabilidad, distractores, la desconfianza, su orgullo y sentimientos negativos lo que las llevó a experimentar desesperanza. Estos resultados concuerdan con lo expuesto por Ruiz Jarabo y Blanco (2004), acerca de que la auto exigencia se encuentra presente cada vez más en la vida cotidiana de las mujeres.

Por su parte, los hombres ubican a factores externos como problemas familiares, falta de dinero, falta de tiempo como los causantes de la desesperanza, lo que corrobora lo escrito por Gray (2003) acerca de que los hombres generalmente se dirigen hacia la evasión de conflictos y a la no búsqueda de alternativas de solución.

Respecto a los malestares corporales, ambos sexos experimentaron dolor de estómago, garganta cerrada, cansancio, dolor de espalda, presión en el pecho, problemas de presión, falta de aire, dolor de cabeza, y malestares psicológicos como mal humor, estos resultados son similares a los mostrados por Torres, Valdez Medina, González Arratia y González (2013) y Valdez Medina, Apolinar, López, Maya, Aguilar, González Arratia y Camacho (2014), respecto a la somatización ante la presencia de emociones negativas.

Un dato que llama especialmente la atención fue la presencia de malestares corporales y psicológicos en la muestra femenina, lo que las ubica en una situación proclive a padecer alguna enfermedad (González y Landero, 2008) o algún trastorno psicológico como la depresión o la ansiedad (Phillips y First, 2009; Wisner y Dolan-Sewell, 2009).

Las respuestas de los participantes ante la experiencia de desesperanza se dirigen hacia la movilidad y la inmovilidad. Los hombres tienden hacia la movilidad, es decir, hacia alejarse, conseguir trabajo, tomarse un tiempo para pensar, lo que corrobora lo expuesto por Gray (2003), referente a que los hombres generalmente se orientan hacia la evasión de conflictos. Mientras que las mujeres adoptan situaciones de inmovilidad como el llanto, deprimirse, desesperarse, enojarse y resignarse, porque culturalmente se les permite más la expresión de las emociones (Díaz Guerrero, 1982; Hurlock, 1987; Valdez Medina, Díaz Loving y Pérez, 2005)

A pesar de que la mayoría de los participantes argumentan haber superado la situación que les generó desesperanza aún existe un alto porcentaje de participantes que lo mantienen presente de alguna manera en sus vidas. Lo cual representa un riesgo, ya que de no resolverse favorablemente esta situación, podría tener un impacto negativo en la salud del individuo (Fernández y Fernández, 1998; Torres, 2013).

\section{REFERENCIAS}

Aguilar, Y.P., Valdez-Medina, J.L y González Arratia, N.I. (2012). Satisfacción con los roles de género. Revista Electrónica de Psicología Iztacala. UNAM. 15(4), 1440-1453.

Alvarado, O. J. (2014). Frustración, odio y culpa, el origen de la personalidad en conflicto. (Tesis de Maestría inédita). Universidad Autónoma del Estado de México, UAEMéx, Toluca, México.

American Psychiatric Association (APA) (1994). Diagnostic and Statistical Manual of Mental Disorders DSM-IV. Washington: American Psychiatric Press.

Beck,A.T. (1976). Cognitive therapy and the emotional disorders. New York: The New American Library, Inc.

Beck, A.T., Weissman, A., Lester, D. y Trextler, A. (1974). The measurement of pessimism: The Hopelessness Scale. Journal of Consulting and Clinical Psychology, 42(6), 861-865.

Briceño L., R. (1991). Las expectativas de futuro y la crisis. Espacio Abierto, 1(1), 5-18.

Buss D. (2005). La evolución del deseo. España: Alianza

Cisneros, A. y Zubillaga, V. (2001). La violencia desde la perspectiva de la víctima: la construcción social del miedo. Espacio Abierto, 6(1), 71-97.

Córdova, M, Rosales, J. C y Eguiluz, L. (2005). La didáctica constructiva de una escala de 
desesperanza: resultados preliminares. Enseñanza e investigación en psicología, 10 (2), 311-324.

Córdova, M. y Rosales, J.C. (2010) La desesperanza de riesgo en jóvenes mexicanos y aspectos sociodemográficos asociados: diferencias por sexo. Psicología y salud, 20 (2), 195-201.

Díaz Loving R., Díaz Guerrero, R., Heilmreich, R. y Spence, J. (1981). Comparación transcultural y análisis psicométrico de una medida de rasgos masculinos (instrumentales) y femeninos (expresivos). Revista latinoamericana de Psicología social, 1 (1), 3-38.

Díaz Guerrero, R (1982). Psicología del mexicano. Descubrimiento de la etnopsicología. México: Trillas.

Fernández R. y Fernández C. (1998). Actitudes hipocondríacas, síntomas somáticos y afecto negativo. Psicothema, 10 (2), 259-70

Garay, J y Farfán, M. (2007). Niveles de depresión, autoestima y estrés en mujeres que tienen un trabajo remunerado y mujeres que tienen un trabajo no remunerado. Psicología iberoamericana. 15 (2). 22-29.

González, J y Hernández, A. (2012). La desesperanza aprendida y sus predictores en jóvenes: Análisis desde el modelo de Beck. Enseñanza $e$ investigación en psicología. 17 (2), 313-327.

González, M. y Landero, R. (2008). Síntomas psicosomáticos y estrés: comparación de un modelo estructural entre hombres y mujeres. México: UANL.

Gray, J. (2003) Los hombres son de Marte, las mujeres son de Venus. México: Océano.

Hurlock, B. (1987) Psicología de la adolescencia. México: Paidós.

La Frombiose, T., y Pitney. B (1995), The Zuni life skills development curriculum: Description and evaluation of a suicide prevention program. Journal of counseling Psychology, 42, 479-486.

Phillips, K.A. y First, M.B. (2009). Introducción. En W.E. Narrow, M.B. First, P.J. Sirovatka y D.A. Regier (Eds.). Agenda de investigación para el DSM-V. Consideraciones sobre la edad y el

Fecha de recepción: 20 de octubre de 2014

Fecha de aceptación: 5 de noviembre de 2014 género en el diagnóstico psiquiátrico (pp. 3-6) Barcelona: Elsevier Masson.

Pichot, P. (1995). DSM IV: Breviario, Criterios Diagnósticos. España: Masson.

Quintanilla, Q., Haro, L.P., Flores, M. E., Celis, A y Valencia, S. (2003). Desesperanza y tentativa suicida. Investigación en salud. 5 (2), 2-8.

Ruiz Jarabo, C y Blanco, P (2004). La violencia contra las mujeres: prevención y detección. Madrid: Díaz de Santos.

Seligman, M. E. P. (1975). Helplessness: On Depression, Development, and Death. San Francisco: W.H. Freeman.

Torres,M,A.(2013) Características de personalidad en adultos que presentan síntomas somáticos. (Tesis de Maestría inédita). Universidad Autónoma del Estado de México, UAEMéx, Toluca, México.

Torres, M. M., Valdez Medina, J. L, González Arratia, N. I y González, S. (2013) Personalidad en caos o entrópica y su asociación con la presencia de síntomas somáticos. Revista Electrónica de Iztacala. 16 (1), 144-158.

Valdez Medina J. L., Apolinar, A., López, S., Maya, M., Aguilar, Y. P, González Arratia, N. I. y Camacho, K. (2014). Frustración, odio y somatización: un análisis por sexo. Revista internacional PEI: por la psicología y educación integral. 3 (6), 72-94.

Valdez Medina, J. L. (2009). Teoría de la Paz y el Equilibrio: una nueva teoría que explica las causas del miedo y del sufrimiento y que nos enseña a combatirlo. México: Edamex.

Valdez Medina, J.L, Díaz Loving, R. y Pérez, R. (2005). Los hombres y las mujeres en México: dos mundos distantes y complementarios. México: UAEM

Wisner, K.L. y Dolan-Sewell, R. (2009). ¿Por qué tiene importancia el género? En: W.E. Narrow, M.B. First, P.J. Sirovatka y D.A. Regier (Eds.). Agenda de investigación para el DSM-V. Consideraciones sobre la edad y el género en el diagnóstico psiquiátrico (pp. 7-17). Barcelona: Elsevier Masson 